Article

\title{
Liver Fibrosis Assessment with Diffusion-Weighted Imaging: Value of Liver Apparent Diffusion Coefficient Normalization Using the Spleen as a Reference Organ
}

\author{
Min Ki Shin ${ }^{1}$, Ji Soo Song ${ }^{1,2,3, *}$, Seung Bae Hwang ${ }^{1,2,3}$, Hong Pil Hwang ${ }^{4}$, Young Jun Kim ${ }^{5}$ \\ and Woo Sung Moon ${ }^{6}$ \\ 1 Department of Radiology, Chonbuk National University Medical School and Hospital, Jeonju 54907, Korea; \\ arakd123@gmail.com (M.K.S.); sbh1010@jbnu.ac.kr (S.B.H.) \\ 2 Research Institute of Clinical Medicine of Chonbuk National University, Jeonju 54907, Korea \\ 3 Biomedical Research Institute of Chonbuk National University Hospital, Jeonju 54907, Korea \\ 4 Department of Surgery, Chonbuk National University Medical School, Jeonju 54907, Korea; \\ tzangke@hanmail.net \\ 5 Department of Radiology, Presbyterian Medical Center, Jeonju 54907, Korea; turtle28@naver.com \\ 6 Department of Pathology, Chonbuk National University Medical School, Jeonju 54907, Korea; \\ mws@jbnu.ac.kr \\ * Correspondence: pichgo@gmail.com; Tel.: +82-63-250-1150
}

Received: 31 July 2019; Accepted: 27 August 2019; Published: 28 August 2019

\begin{abstract}
Liver fibrosis staging is of great clinical importance because it is used to assess the severity of the underlying chronic liver disease. Among various imaging-based methods, apparent diffusion coefficient (ADC) measurement using diffusion-weighted imaging (DWI) has the potential to be used as an imaging biomarker for liver fibrosis assessment. In this study, we investigated the usefulness of liver ADC normalization using the spleen as a reference organ in liver fibrosis staging with 66 patients who underwent liver magnetic resonance imaging (MRI), transient elastography (TE), and surgical resection of a hepatic mass. ADC values of the liver $\left(\mathrm{ADC}_{\text {liver }}\right)$ and spleen were analyzed, and the spleen was used for $\mathrm{ADC}_{\text {liver }}$ normalization ( $\mathrm{ADC}_{\text {liver }}$ ). $\mathrm{ADC}_{\text {liver }}$ showed a weak negative correlation with TE $(r=-0.246 ; p=0.047)$ and fibrosis stage $(r=-0.269 ; p=0.029)$, while $\mathrm{n} \mathrm{ADC}_{\text {liver }}$ showed a moderate negative correlation with TE $(r=-0.504 ; p<0.001)$ and fibrosis stage $(r=-0.579$; $p<0.001)$. AUC values for $\mathrm{nADC}_{\text {liver }}(0.777-0.875)$ were higher than those for $\mathrm{ADC}_{\text {liver }}$ for each stage

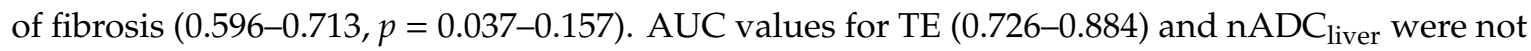
statistically different. In conclusion, normalized liver ADC can be useful in diagnosing liver fibrosis stage in patients with variable DWI acquisitions.
\end{abstract}

Keywords: fibrosis; liver cirrhosis; spleen; diffusion magnetic resonance imaging; magnetic resonance imaging

\section{Introduction}

Liver fibrosis is characterized by excessive deposition of extracellular matrix proteins in response to injury and failure of cellular repair efforts to degrade these deposits. Liver fibrosis can progress to cirrhosis, which puts patients at a higher risk for hepatocellular carcinoma (HCC) and hepatic decompensation. As a result, identification of fibrosis precisely over the entire pathologic spectrum, from early-stage fibrosis to cirrhosis, is of considerable clinical importance for managing patients with chronic liver disease [1]. In addition, early detection of fibrosis is important because of the potential to prevent fibrosis progression, or even its reversal by elimination of causative factors [2]. 
Many noninvasive image-based methods to assess liver fibrosis have been investigated, including transient elastography (TE), magnetic resonance elastography (MRE), diffusion-weighted imaging (DWI), perfusion-weighted imaging, and MR spectroscopy [3-5]. Liver stiffness measurements using TE have been widely studied, and TE is efficient in measuring liver stiffness by elastic shear wave propagation through the liver [6,7]. However, its applicability can be limited by patient obesity, the presence of ascites, or limited operator experience [8]. In contrast, DWI can be added easily to a routine MR protocol, providing anatomic and structural information as well as measurement of quantitative metrics, such as the apparent diffusion coefficient (ADC). Many studies have shown that the ADC can be used to detect and stage liver fibrosis [9-11]. However, reported ADC values vary between studies due to the influence of many factors, including MR system hardware, patient characteristics, motion artifacts, acquisition parameters, and susceptibility effects [12,13]. Further, to use ADC values as an imaging biomarkers or prognostic parameters in longitudinal or multicenter studies, it is important to standardize ADC measurements.

A previous study of patients undergoing many rounds of MRI at various times with variable acquisition parameters reported that an ADC normalized using the spleen for a reference organ significantly reduced variability in ADC measurements for upper abdominal organs [14]. In order to qualify as a reference, the comparison organ should be similarly affected by diffusion parameters as the examined organ. The spleen could be a suitable reference organ, as it has been shown to have a comparatively non-variable ADC value across different diseases, and its ADC value can be used for quantitative analysis with ratios as needed [15]. In addition, the spleen is often added in liver MR imaging, and is a well-perfused organ.

The purpose of this study was to evaluate the feasibility of using a normalized ADC with the spleen as the reference organ for liver fibrosis assessment by (1) evaluating correlations between TE values and both standard and normalized ADC measurements, respectively, and between pathologic liver fibrosis staging and both standard and normalized ADC measurements, respectively, in patients with variable DWI acquisition parameters and (2) comparing the diagnostic performance of normalized $\mathrm{ADC}$ and TE in fibrosis evaluation relative to the gold standard of liver biopsy.

\section{Materials and Methods}

\subsection{Subjects}

This study was approved by institutional review board of the Chonbuk National University Hospital (IRB file No. 2018-02-014-001; approved date, 23 March, 2018) and patient informed consent was waived for reviewing patient images and records. From June 2010 to February 2018, 138 patients undergoing MR imaging of the liver, including DWI, and surgical resection of a hepatic mass were retrospectively reviewed. Of these patients, 55 were excluded for reasons as follows: (1) 40 patients did not have TE measurements; (2) Eight patients had either a very large hepatic mass or multiple masses, which hindered liver ADC measurement; and (3) Seven patients were noted to have severe susceptibility artifacts on DWI. Our final study population of 83 patients included 65 men and 18 women with a mean age of 58.4 years. Of these patients, $76(91.6 \%)$ had chronic hepatitis from the following causes: chronic hepatitis B $(n=57)$, alcoholism $(n=10)$, chronic hepatitis $\mathrm{C}(n=3)$, and unknown $(n=6)$.

\subsection{MR Imaging Techniques}

Liver MR imaging was acquired using three 3.0 T MR systems (Verio and Skyra, Siemens Healthineers, Erlangen, Germany; Achieva TX, Philips Healthcare, Best, the Netherlands). Hepatobiliary and dynamic phases were initiated following bolus injection of gadoxetic acid (Eovist or Primovist; Bayer Healthcare, Berlin, Germany). DWI was obtained between the 10- and 20-min hepatobiliary phase.

DWI was executed using either a free-breathing or navigator-triggered method. Various $b$ value combinations were used, which included $b_{1}=0,50,400,800 ; b_{2}=0,50,600 ;$ and $b_{3}=50,400,800 \mathrm{~s} / \mathrm{mm}^{2}$. Acquisition parameters are presented in Table 1. 
Table 1. Parameters for diffusion-weighted imaging (DWI) acquisition.

\begin{tabular}{|c|c|c|c|c|c|}
\hline \multirow{2}{*}{$\begin{array}{c}\text { Parameter } \\
\text { Sequence }\end{array}$} & \multicolumn{2}{|c|}{ Verio } & \multicolumn{2}{|c|}{ Achieva } & \multirow{2}{*}{$\begin{array}{c}\text { Skyra } \\
\text { SE-EPI }\end{array}$} \\
\hline & SE-EPI & SE-EPI & SE-EPI & SE-EPI & \\
\hline Respiration & FB & NT & FB & NT & FB \\
\hline TR/TE (msec) & $11500 / 67$ & $2800 / 65$ & $8750 / 66$ & $1422 / 56$ & $5100 / 66$ \\
\hline $\mathrm{FOV}(\mathrm{mm})$ & $400 \times 400$ & $380 \times 285$ & $400 \times 400$ & $350 \times 350$ & $370 \times 278$ \\
\hline Matrix & $128 \times 128$ & $128 \times 96$ & $128 \times 128$ & $128 \times 124$ & $128 \times 96$ \\
\hline $\mathrm{ST}(\mathrm{mm})$ & 5 & 6 & 5 & 6 & 5 \\
\hline $\begin{array}{l}\text { Intersection gap } \\
\qquad(\mathrm{mm})\end{array}$ & 1 & 1.2 & 1 & 1 & 1 \\
\hline No. of sections & 33 & 29 & 35 & 35 & 34 \\
\hline NSA & 3 & 2 & 3 & 3 & 4 \\
\hline$b$ values $\left(\mathrm{s} / \mathrm{mm}^{2}\right)$ & $b_{1}, b_{3}$ & $b_{1}, b_{3}$ & $b_{1}, b_{2}$ & $b_{1}$ & $b_{1}$ \\
\hline BW $(\mathrm{Hz})$ & 2442 & 2298 & 3743 & 3634 & 2442 \\
\hline PAF & GRAPPA $=2$ & GRAPPA $=2$ & SENSE $=2$ & $\mathrm{SENSE}=2$ & GRAPPA $=2$ \\
\hline Fat saturation & SPAIR $^{1}$ & SPAIR $^{1}$ & SPAIR $^{2}$ & SPAIR $^{2}$ & SPAIR $^{1}$ \\
\hline Scan time & $5: 50$ & $5: 15$ & $5: 35$ & 4:00 & $3: 50$ \\
\hline EPI factor & 96 & 96 & 65 & 65 & 96 \\
\hline
\end{tabular}

$\mathrm{TR}=$ repetition time, $\mathrm{TE}=$ echo time, $\mathrm{FOV}=$ field of view, $\mathrm{NT}=$ navigator-triggered, $\mathrm{SE}-\mathrm{EPI}=$ spin echo-echo planar imaging, FB = free breathing, PAF = parallel acquisition factor, NSA = number of signals acquired, $\mathrm{BW}=$ bandwidth, GRAPPA $=$ generalized autocalibrating partially parallel acquisition, SPAIR $^{1}=$ spectrally adiabatic inversion recovery, $\mathrm{ST}=$ slice thickness, $\mathrm{SPAIR}^{2}=$ spectral attenuated inversion recovery, $\mathrm{SENSE}=$ sensitivity encoding, $b_{1}=0$, $50,400,800 ; b_{2}=0,50,600 ; b_{3}=50,400,800 \mathrm{~s} / \mathrm{mm}^{2}$.

\subsection{Quantitative Image Analysis}

Maps of ADC values were generated automatically with mono-exponential fitting for all $b$ values. A radiologist with two years of experience in MR imaging determined regions of interest (ROIs) for all anatomic regions on the ADC images with a picture archiving and communication (PACS) system (Maroview 5.4; Marotech, Seoul, Korea). In accordance with anatomic regions studied and patient characteristics, the ROI sizes were various (range, $2-8 \mathrm{~cm}^{2}$ ). Each ROI was similarly positioned on a corresponding ADC map through the PACS system. The right and left liver lobes and the spleen were the anatomic regions analyzed. For the right and left liver lobes, two ROIs from three contiguous slices were measured, with a central section obtained through the level of the right portal vein for the right lobe and the umbilical portion of the left portal vein for the left lobe. For the spleen, two ROIs from three contiguous slices were determined, with a central section obtained through the level of the splenic hilum. In total, 18 ROIs were determined per patient. For ADC that was non-normalized, the values were absolute; nevertheless, the values are relative and are represented by a ratio with normalized ADC. Normalized ADC may be able to achieve greater standardization across different parameters or different devices, as these differences may be minimized by normalization. Regarding the normalization calculations, the $\mathrm{ADC}$ values of liver regions $\left(\mathrm{ADC}_{\text {liver }}\right)$ were divided by the spleen $\mathrm{ADC}$ values and denoted $n A D C_{\text {liver. }}$. For liver stiffness measurements using TE, a FibroScan system (Echosens, Paris, France) equipped with the standard probe (M-probe) was used as previously described $[7,16]$.

\subsection{Histopathologic Evaluation}

Surgical treatment of the patients included in the final analysis included 30 who underwent segmentectomy, 20 who had sectionectomy, 18 who underwent wedge resection, 10 who had hepatectomy, and five who were treated with liver transplantation. Liver fibrosis stage of all surgical specimens was evaluated by a senior hepatopathologist with more than 23 years of experience using the METAVIR scoring system; stage F0, no fibrosis; stage F1, portal fibrosis; stage F2, periportal fibrosis; stage F3, septal fibrosis; and stage F4, cirrhosis.

\subsection{Statistical Analysis}

The Shapiro-Wilk test was used to assess normality of the continuous variables. Correlations between TE values and liver ADC value (before and after normalization), respectively, and liver fibrosis 
stage were investigated using Spearman's rank correlation test. In addition, correlation between liver ADC value (before and after normalization) and TE values were explored using the Pearson correlation test. The area under the receiver operating characteristic (ROC) curve (AUC value) and the optimal cut-off value were calculated for differentiating fibrosis stages $\geq F 1$ from $F 0, \geq F 2$ from $\leq F 1, \geq F 3$ from $\leq \mathrm{F} 2$, and $\mathrm{F} 4$ from $\leq \mathrm{F} 3$. The cut-off was determined by the maximum sum of sensitivity and specificity values. AUC values were compared using the jackknife method [17]. Statistical analysis was performed using commercially available software (SPSS v23.0; IBM, Armonk, NY, USA or MedCalc v13.0.0.0; MedCalc Software, Ostend, Belgium). $p$ values lower than 0.05 were considered significant.

\section{Results}

\subsection{DWI Acquisition Methods}

For the 83 examinations in our patient population, the MR system used most was Verio (45 examinations, 54.2\%), then Achieva (20 examinations, 24.1\%), and then Skyra (18 examinations, 21.7\%). Of the two respiratory motion compensation methods, free breathing was used more frequently than navigator triggering $(72.7 \%$ vs. $27.3 \%)$. For $b$ value parameters, a $b$ value combination of $0,50,400$, and $800\left(b_{1}\right)$ was used most (48 examinations, $72.7 \%$ ) (Table 2 ).

Table 2. DWI acquisition methods.

\begin{tabular}{|c|c|c|c|c|c|c|c|}
\hline \multirow{2}{*}{$b$ Value } & \multicolumn{2}{|c|}{ Verio } & \multicolumn{2}{|c|}{ Achieva } & \multicolumn{2}{|c|}{ Skyra } & \multirow{2}{*}{ No. of Examinations } \\
\hline & FB & NT & FB & NT & FB & NT & \\
\hline$b_{1}$ & 26 & 2 & 12 & 3 & 18 & & $61(73.5 \%)$ \\
\hline$b_{2}$ & & & 4 & & & & $4(4.8 \%)$ \\
\hline \multirow[t]{3}{*}{$b_{3}$} & 3 & 15 & & & & & $18(21.7 \%)$ \\
\hline & 46 & $\%)$ & 19 & $9 \%)$ & 18 & $7 \%)$ & \multirow{2}{*}{$83(100 \%)$} \\
\hline & \multicolumn{6}{|c|}{$\mathrm{NT}=20(24.1 \%), \mathrm{FB}=63(75.9 \%)$} & \\
\hline
\end{tabular}

\subsection{Histopathologic Results}

Based on the METAVIR scoring system, the following fibrosis stage distribution was observed: stage F0 $(n=13)$, stage F1 $(n=8)$, stage F2 $(n=11)$, stage F3 $(n=26)$, and stage F4 (cirrhosis, $n=25)$ (Figure 1$)$.
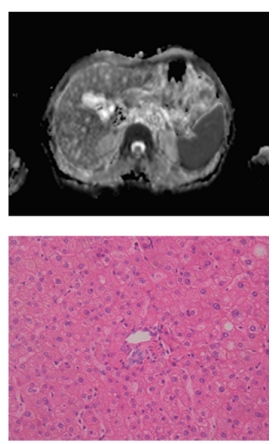

(a)
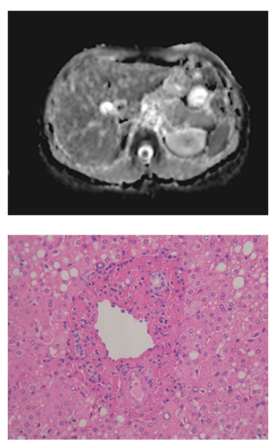

(b)
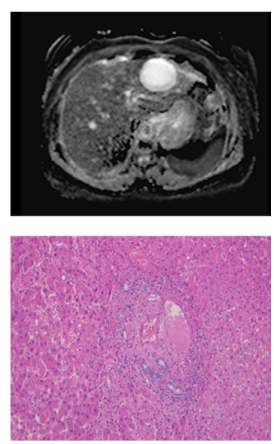

(c)
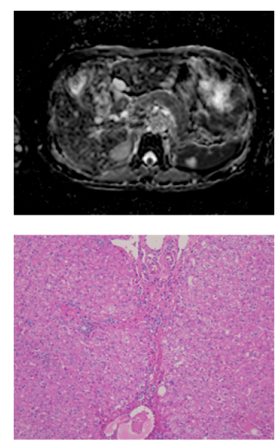

(d)
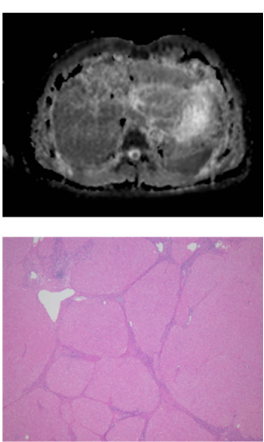

(e)

Figure 1. Magnetic resonance imaging (apparent diffusion coefficient (ADC) map, upper row) and histologic findings (H\&E stain, lower row) matched for each stages of liver fibrosis. (a) No liver fibrosis (F0), magnification $\times 400$. $A D C_{\text {liver }}$ was $1.389 \times 10^{-3} \mathrm{~mm}^{2} / \mathrm{s}$ and $\mathrm{nADC}$ liver was 1.977. (b) Portal fibrosis (F1), magnification $\times 400$. $\mathrm{ADC}_{\text {liver }}$ was $1.091 \times 10^{-3} \mathrm{~mm}^{2} / \mathrm{s}$ and $\mathrm{nADC}_{\text {liver }}$ was 1.327. (c) Periportal fibrosis (F2), magnification $\times 400 . \mathrm{ADC}_{\text {liver }}$ was $1.376 \times 10^{-3} \mathrm{~mm}^{2} / \mathrm{s}$ and $\mathrm{nADC}_{\text {liver }}$ was 1.416 . (d) Septal fibrosis (F3), magnification $\times 200$. $\mathrm{ADC}_{\text {liver }}$ was $0.963 \times 10^{-3} \mathrm{~mm}^{2} / \mathrm{s}$ and $\mathrm{nADC}_{\text {liver }}$ was 1.29. (e) Cirrhosis (F4), magnification $\times 20$. $\mathrm{ADC}_{\text {liver }}$ was $1.278 \times 10^{-3} \mathrm{~mm}^{2} / \mathrm{s}$ and $\mathrm{nADC}_{\text {liver }}$ was 1.355 . 


\subsection{Correlations Between Fibrosis Stage, TE Value, Liver ADC and Normalized Liver ADC}

We observed a weak negative correlation between TE values and $\mathrm{ADC}_{\text {liver }}(r=-0.256$, [95\% CI: $-0.450-0.014] ; p=0.045)$, while a moderate negative correlation was noted between TE values and $\mathrm{nADC}_{\text {liver }}(r=-0.523$, [95\% CI: $\left.-0.647-0.275] ; p<0.001\right)$. In addition, there was a weak negative correlation between fibrosis stage and $\mathrm{ADC}_{\text {liver }}(r=-0.281$ [95\% CI: $-0.471-0.018$ ]; $p=0.026)$, while a moderate negative correlation was observed between fibrosis stage and $\mathrm{nADC}_{\text {liver }}(r=-0.584[95 \%$ CI: -0.703-0.382]; $p<0.001$ ) (Figure 2). Finally, we observed a moderate positive correlation between fibrosis stage and TE values ( $r=0.665$, [95\% CI: 0.502-0.771]; $p<0.001)$.

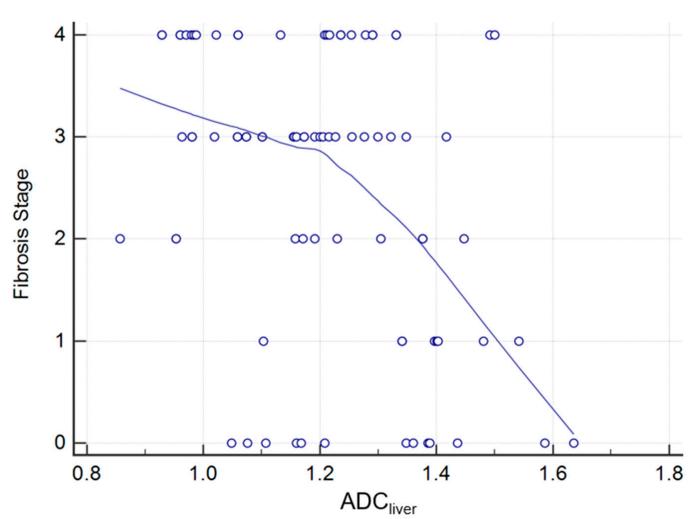

(a)

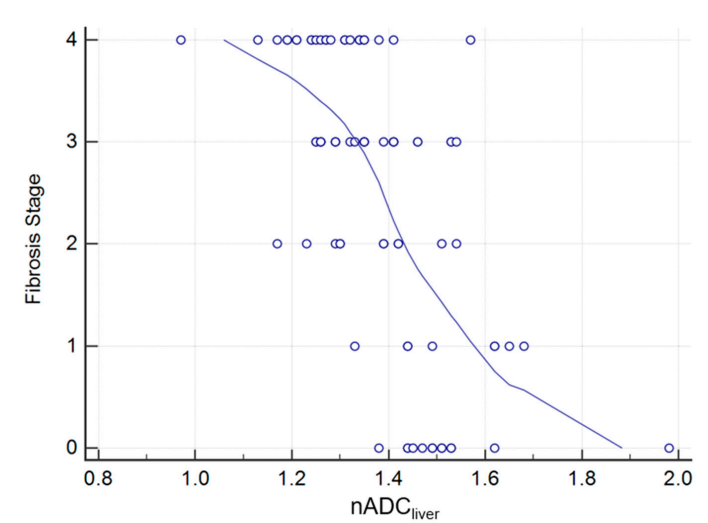

(b)

Figure 2. Scatter plot of Spearman's rank correlation test between liver fibrosis stage and liver ADC before (a) and after (b) normalization.

\subsection{Diagnostic Performance and Cut-off Value Evaluation}

According to $\mathrm{ROC}$ analysis, $\mathrm{nADC}_{\text {liver }}$ exhibited a good diagnostic performance for each stage of fibrosis, with $\mathrm{AUCs}$ higher than those of $\mathrm{ADC}_{\text {liver }}$. Comparing $\mathrm{n} \mathrm{ADC}_{\text {liver }} \mathrm{vs} \mathrm{ADC}_{\text {liver }}$, our results were as follows: (1) for fibrosis stage $\geq \mathrm{F} 1,0.863$ vs $0.625(p=0.064)$; (2) for fibrosis stage $\geq \mathrm{F} 2,0.877$ vs 0.631 ( $p=0.031)$; (3) for fibrosis stage $\geq \mathrm{F} 3,0.764$ vs $0.587(p=0.114)$; and (4) for fibrosis stage F4, 0.789 vs 0.577 ( $p=0.041)$. The optimal cut-off values of $\mathrm{nADC}_{\text {liver }}$ were $1.443,1.411,1.396$, and 1.365 for diagnosing $\geq F 1, \geq F 2, \geq F 3$, and F4, respectively (Table 3) (Figure 3). AUC values of TE for diagnosing $\geq F 1, \geq F 2, \geq F 3$, and $F 4$ were $0.799,0.811,0.721$, and 0.884 respectively, none of which were significantly different from comparable values for $n \mathrm{ADC}_{\text {liver }}(p>0.05)$ (Table 4) (Figure 4).

Table 3. Comparison between liver ADC and $\mathrm{nADC}$ liver.

\begin{tabular}{cccc}
\hline Variable & Liver ADC & nADC $_{\text {liver }}$ & $p$ Value \\
\hline F1 $(n=8)$ & & & \\
Optimal cut-off value & $1.347\left(\times 10^{-3} \mathrm{~mm}^{2} / \mathrm{s}\right)$ & $78.2(64.7,89.1)$ & \\
Sensitivity $(\%)$ & $83.1(71.2,91.7)$ & $91.0(67.6,99.2)$ & \\
Specificity $(\%)$ & $57.2(24.3,85.3)$ & $0.863(0.755,0.952)$ & 0.064 \\
AUC $(95 \%$ CI) & $0.625(0.501,0.727)$ & & \\
\hline F2 $(n=11)$ & & 1.411 & \\
Optimal cut-off value & $1.332\left(\times 10^{-3} \mathrm{~mm}^{2} / \mathrm{s}\right)$ & $84.3(71.1,91.9)$ & 0.031 \\
Sensitivity (\%) & $83.4(71.8,90.6)$ & $86.9(61.2,98.1)$ & \\
Specificity (\%) & $58.5(30.7,79.9)$ & $0.877(0.772,0.948)$ & \\
AUC $(95 \%$ CI $)$ & $0.631(0.529,0.759)$ & & \\
\hline F3 $(n=26)$ & &
\end{tabular}


Table 3. Cont.

\begin{tabular}{cccc}
\hline Variable & Liver ADC & nADC $_{\text {liver }}$ & $p$ Value \\
\hline Optimal cut-off value & $1.330\left(\times 10^{-3} \mathrm{~mm}^{2} / \mathrm{s}\right)$ & 1.396 & \\
Sensitivity $(\%)$ & $85.4(71.2,92.1)$ & $84.5(69.8,92.1)$ & \\
Specificity $(\%)$ & $44.2(23.6,65.1)$ & $69.2(46.9,85.8)$ & \\
AUC $(95 \%$ CI $)$ & $0.587(0.461,0.694)$ & $0.764(0.645,0.859)$ & \\
\hline F4 $(n=25)$ & & & \\
Optimal cut-off value & $1.189\left(\times 10^{-3} \mathrm{~mm}^{2} / \mathrm{s}\right)$ & 1.365 \\
Sensitivity (\%) & $43.4(22.1,65.7)$ & $90.2(68.2,98.9)$ & \\
Specificity $(\%)$ & $83.1(68.5,90.8)$ & $62.3(46.6,75.8)$ & 0.041 \\
AUC $(95 \% \mathrm{CI})$ & $0.577(0.443,0.689)$ & $0.789(0.671,0.882)$ &
\end{tabular}

Note. $95 \%$ confidence intervals are given in parenthesis for sensitivity, specificity, and AUC.

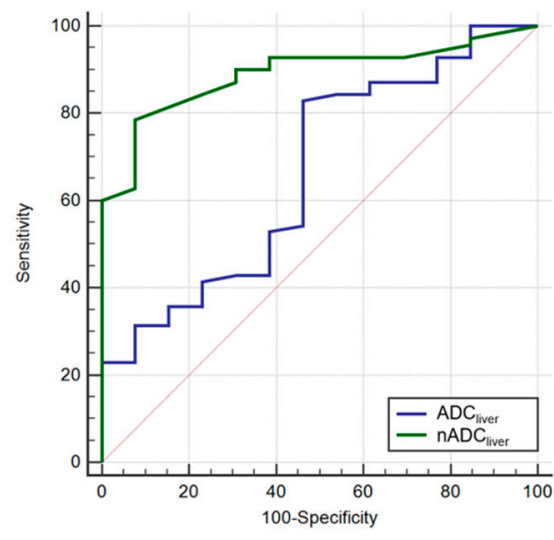

(a)

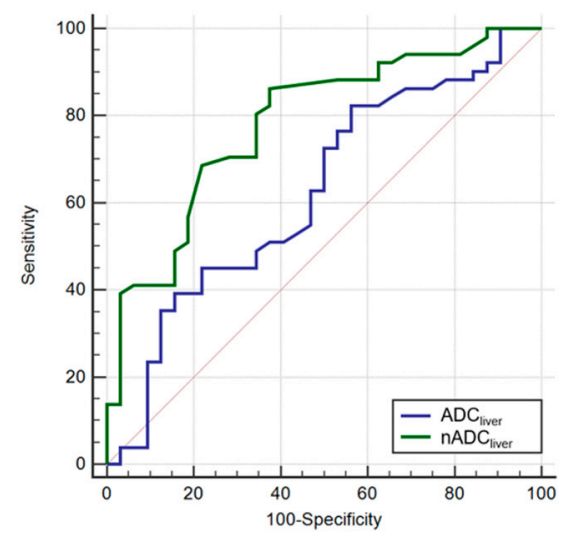

(c)

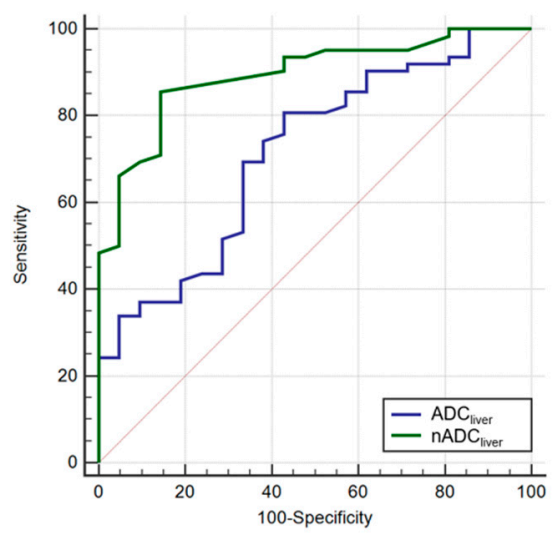

(b)

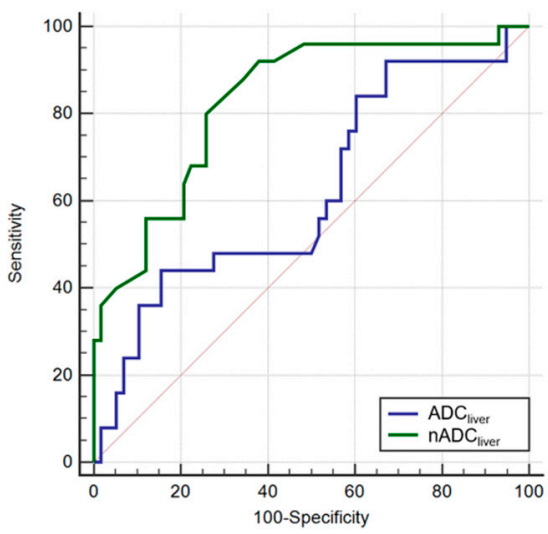

(d)

Figure 3. Comparison of receiver operating characteristics curve for diagnosing fibrosis stage $\geq \mathrm{F} 1$ (a), $\geq \mathrm{F} 2(\mathbf{b}), \geq \mathrm{F} 3(\mathbf{c})$, and F4 (d) on liver ADC (ADC liver) and normalized ADC (nADC liver).

Table 4. Comparison between $\mathrm{TE}$ and $\mathrm{nADC}$ liver.

\begin{tabular}{cccc}
\hline Variable & TE & nADC $_{\text {liver }}$ & $p$ Value \\
\hline F1 $(n=8)$ & & & \\
Optimal cut-off value & $5.9(\mathrm{kPa})$ & 1.443 & \\
Sensitivity (\%) & $94.1(84.7,98.8)$ & $78.2(64.7,89.1)$ & \\
Specificity (\%) & $58.2(26.2,88.2)$ & $91.0(67.6,99.2)$ & \\
AUC $(95 \%$ CI $)$ & $0.799(0.683,0.888)$ & $0.863(0.755,0.952)$ & 0.612 \\
\hline F2 $(n=11)$ & & & \\
\hline
\end{tabular}


Table 4. Cont.

\begin{tabular}{|c|c|c|c|}
\hline Variable & TE & nADC $_{\text {liver }}$ & $p$ Value \\
\hline Optimal cut-off value & $6.9(\mathrm{kPa})$ & 1.411 & \\
\hline Sensitivity (\%) & $88.2(75.8,95.3)$ & $84.3(71.1,91.9)$ & \\
\hline Specificity (\%) & $68.8(41.5,89.2)$ & $86.9(61.2,98.1)$ & \\
\hline AUC $(95 \%$ CI) & $0.811(0.718,0.882)$ & $0.877(0.772,0.948)$ & 0.892 \\
\hline \multicolumn{4}{|l|}{ F3 $(n=26)$} \\
\hline Optimal cut-off value & $9.0(\mathrm{kPa})$ & 1.396 & \\
\hline Sensitivity (\%) & $65.1(49.0,77.9)$ & $84.5(69.8,92.1)$ & \\
\hline Specificity (\%) & $71.2(50.2,87.1)$ & $69.2(46.9,85.8)$ & \\
\hline AUC $(95 \%$ CI $)$ & $0.721(0.597,0.802)$ & $0.764(0.645,0.859)$ & 0.877 \\
\hline \multicolumn{4}{|l|}{$\mathrm{F} 4(n=25)$} \\
\hline Optimal cut-off value & $9.7(\mathrm{kPa})$ & 1.365 & \\
\hline Sensitivity (\%) & $100(83.2,100)$ & $90.2(68.2,98.9)$ & \\
\hline Specificity (\%) & $69.6(54.2,82.3)$ & $62.3(46.6,75.8)$ & \\
\hline AUC $(95 \%$ CI $)$ & $0.884(0.787,0.943)$ & $0.789(0.671,0.882)$ & 0.064 \\
\hline
\end{tabular}

Note. $95 \%$ confidence intervals are given in parenthesis for sensitivity, specificity, and AUC.

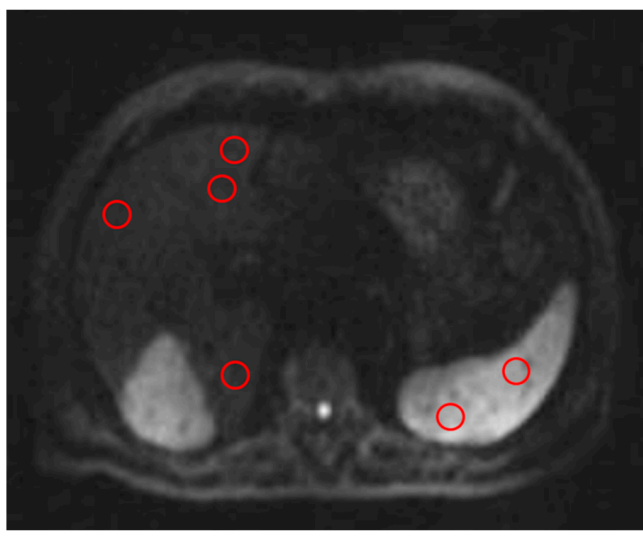

(a)

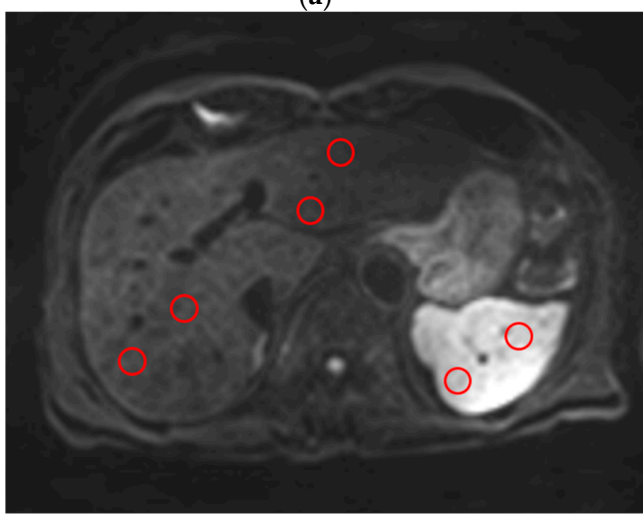

(c)

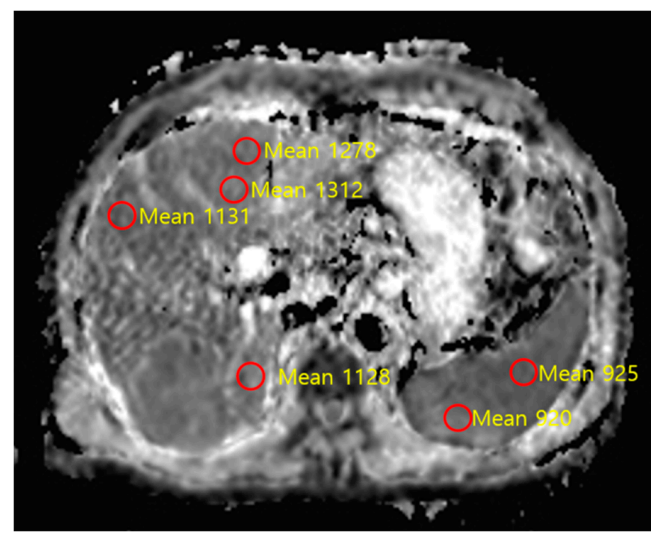

(b)

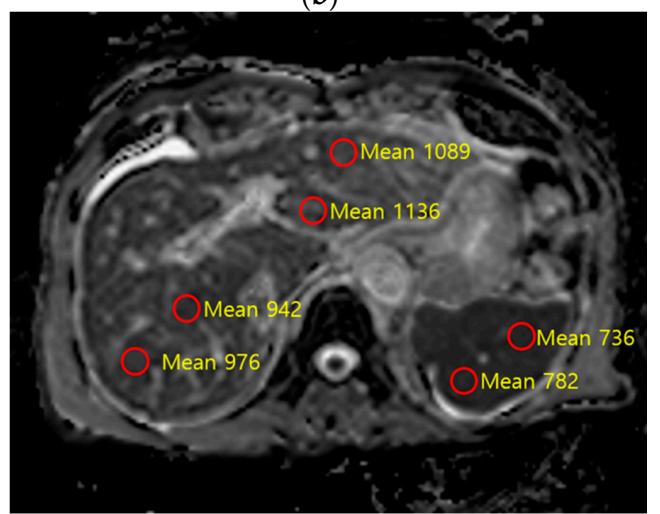

(d)

Figure 4. Two patients who underwent surgical resection for hepatocellular carcinoma (HCC) and pathologically confirmed cirrhosis (F4). Red circle indicates region of interest for ADC value measurement (yellow numbers in $(\mathbf{b}, \mathbf{d})$ ). (a,b) A 77-year old man with viral B cirrhosis, navigator-triggered DWI acquired on Verio with $b=50,400,800 \mathrm{~s} / \mathrm{mm}^{2}$. On $b=800 \mathrm{~s} / \mathrm{mm}^{2}$ (a) and corresponding ADC map (b), the liver ADC was $1.236 \times 10^{-3} \mathrm{~mm}^{2} / \mathrm{s}$ and the normalized ADC was 1.257. The transient elastography value was $13.2 \mathrm{kPa}$. (c,d) A 68-year old man with viral B cirrhosis. Navigator-triggered DWI acquired on Achieva with $b=0,50,400,800 \mathrm{~s} / \mathrm{mm}^{2}$. On $b=800 \mathrm{~s} / \mathrm{mm}^{2}$ (c) and corresponding ADC map (d), the liver ADC was $0.970 \times 10^{-3} \mathrm{~mm}^{2} / \mathrm{s}$ and the normalized ADC was 1.276. The transient elastography value was $12.3 \mathrm{kPa}$. 


\section{Discussion}

In this study, we observed moderate negative correlations between $\mathrm{nADC}$ liver and both $\mathrm{TE}$ values and fibrosis stage ( $r=-0.523$ and -0.584 , respectively). $\mathrm{ADC}_{\text {liver }}$ was negatively correlated with both TE values and fibrosis stage as well, although it was only weakly correlated with both $(r=-0.256$ and -0.281 , respectively). Based on the results of $A U C$, the diagnostic performance of $n A D C_{\text {liver }}$ was superior to $A D C_{\text {liver, }}$, with significant differences in fibrosis staging results for $\geq F 2(p=0.031)$ and $\geq F 4$ $(p=0.041) . \mathrm{nADC}_{\text {liver }}$ demonstrated good diagnostic performance in diagnosing all stages of fibrosis in comparison to TE ( $p>0.05$, no significant differences between the parameters).

Previous studies have reported ADC values of patients with liver fibrosis are significantly lower than those of normal controls and ADC values decrease as the degree of fibrosis progresses $[9,10]$. A possible explanation for this phenomenon is that since fibrotic liver tissue has abundant proton-poor connective tissue, both blood flow and water diffusion are restricted, which results in a decrease in its ADC values [18]. Although liver biopsy is often contraindicated in patients with advanced cirrhosis, due to the presence of ascites, coagulopathy, and other co-morbidities, it is still regarded as the gold standard for liver fibrosis staging. The use of DWI in patients with contraindications for liver biopsy has significant clinical impact due to its wide availability and relative safety [11]. Nevertheless, a lack of standardized techniques for DWI acquisition is a significant drawback when using ADC as an imaging biomarker for longitudinal multicenter studies, as reported ADC values vary widely with considerable overlap between normal and abnormal ranges. In addition, good reproducibility of ADC measurements is necessary, along with optimization and standardization of techniques for DWI acquisition. Previous studies have reported that reasonable reproducibility levels can be obtained with ADC measurements of the upper abdomen for patients and volunteers $[19,20]$. In the current study, with the use of variable $b$ value combinations, the optimal cut-off value for diagnosing cirrhosis (F4) was $1.189 \times 10^{-3} \mathrm{~mm}^{2} / \mathrm{s}$, with an AUC value of 0.577 . When using $\mathrm{nADC}_{\text {liver }}$, the AUC value increased to 0.789 , which was significantly higher than that of $\mathrm{ADC}_{\text {liver }}(p=0.041)$. We theorize that since most of our DWI studies $\left(73.5 \%\right.$ ) were performed with $b$ values of $0,50,400$, and $800 \mathrm{~s} / \mathrm{mm}^{2}$, this fact may explain both the correlation between $\mathrm{ADC}_{\text {liver }}$ and pathologic fibrosis and the somewhat comparable diagnostic performance of $\mathrm{ADC}_{\text {liver }}$ and $\mathrm{nADC}_{\text {liver }}$.

It is widely accepted that significant fibrosis (F2) is a predictor of future liver cirrhosis and that the ultimate goal of treatment at this stage is to cure the patient by eliminating the underlying cause of liver disease. In addition, maximum accuracy in the detection of advanced fibrosis (F3) or cirrhosis (F4) is important, since these patients should be screened for portal hypertension and HCC [21]. Our study revealed significantly higher AUC values of $n A D C_{\text {liver }}$ for diagnosing significant fibrosis $(\geq \mathrm{F} 2, p=0.031)$ and cirrhosis $(\mathrm{F} 4, p=0.041)$ compared to $\mathrm{ADC}_{\text {liver }}$; and these values were comparable to those in previous studies without normalization of ADC, which showed AUC values of $0.730-0.935$ for the detection of cirrhosis $[3,15,22]$. However, this is the first study to use variable DWI acquisition parameters as well as different MR systems to evaluate liver fibrosis. It demonstrated that normalization of ADC values, using the spleen as the reference organ, significantly increased their diagnostic performance for diagnosing $\geq \mathrm{F} 2$ and $\mathrm{F} 4$.

Transient elastography (TE) has been studied in large patient cohorts for liver fibrosis and cirrhosis detection $[6,23]$. Interestingly, there was no significant difference in diagnostic performance between $\mathrm{TE}$ and $\mathrm{nADC} \mathrm{C}_{\text {liver }}$ in relation to fibrosis. Although $\mathrm{TE}$ measures the stiffness of a liver parenchymal volume 100 times bigger than that of a liver biopsy, it cannot enable segmental tissue analysis or be performed in patients with ascites or obesity [16]. In contrast, DWI includes the whole liver volume with the capability of making ADC measurements for each liver segment, thus providing information about the most severely affected liver segment, and can be performed even in obese patients or patients with ascites [9]. In addition, the multi-parametric nature of MRI itself allows more complete assessment of organ structure and function, such as the ability to quantify hepatic fat and iron content or the use of dynamic contrast enhancement for hepatic perfusion quantification and HCC detection [9]. Based on our study results, MRI may be of value even in patients without previous TE results, since 
the progression of liver fibrosis can be assessed using $\mathrm{nADC}_{\text {liver, }}$ even if the data was acquired with different MR systems or acquisition parameters.

This study has several limitations. First, due to the retrospective nature of the study, it has an inherent selection bias. Second, we studied a heterogeneous patient population with different causes of chronic liver disease and had a limited number of patients with early (F1) and significant (F2) fibrosis. Third, although we used resected liver specimens to stage liver fibrosis, it is well known that histopathologic assessment can have high inter- and intraobserver variability, and the reproducibility of these observations could not be examined [2]. Fourth, most of DWI was acquired with $b$ values of 0 , 50,400 , and $800 \mathrm{~s} / \mathrm{mm}^{2}$ (73.5\%). Fifth, DWI was acquired after gadoxetic acid was administered, but any effects of gadoxetic acid while DWI is performed can be dismissed for up to 20 min following injection [24]. Sixth, since we included $b$ values below $150 \mathrm{~s} / \mathrm{mm}^{2}$ which reflects capillary perfusion, our ADC values were biased. Further study using $b$ values above $150 \mathrm{~s} / \mathrm{mm}^{2}$ is warranted.

In conclusion, our study validated the hypothesis that liver ADC normalized using the spleen as a reference has a better diagnostic performance for detecting stages of fibrosis than liver ADC in patients with variable DWI acquisitions. Further, DWI with normalized liver ADC exhibited comparable diagnostic performance to TE. Future prospective studies with larger patient cohorts and more variation in acquisition parameters and MR systems are necessary to confirm our results and promote application of normalized ADC values.

Author Contributions: Conceptualization, J.S.S.; methodology, J.S.S., M.K.S.; validation, S.B.H., Y.J.K.; formal analysis, M.K.S.; investigation, J.S.S., M.K.S.; data curation, M.K.S., H.P.H.; writing-original draft preparation, M.K.S.; writing-review and editing, J.S.S.; supervision, J.S.S.; project administration, W.S.M.

Funding: This research received no external funding.

Acknowledgments: This paper was supported by the Fund of Biomedical Research Institute, Chonbuk National University Hospital. The authors thank Wade Martin of Emareye Medical Editing Service for his assistance in editing the article.

Conflicts of Interest: The authors declare no conflict of interest. The funders had no role in the design of the study; in the collection, analyses, or interpretation of data; in the writing of the manuscript, or in the decision to publish the results.

\section{References}

1. Watanabe, H.; Kanematsu, M.; Goshima, S.; Kondo, H.; Onozuka, M.; Moriyama, N.; Bae, K.T. Staging hepatic fibrosis: Comparison of gadoxetate disodium-enhanced and diffusion-weighted MR imaging-Preliminary observations. Radiology 2011, 259, 142-150. [CrossRef] [PubMed]

2. Goodman, Z.D. Grading and staging systems for inflammation and fibrosis in chronic liver diseases. J. Hepatol. 2007, 47, 598-607. [CrossRef] [PubMed]

3. Taouli, B.; Chouli, M.; Martin, A.J.; Qayyum, A.; Coakley, F.V.; Vilgrain, V. Chronic hepatitis: Role of diffusion-weighted imaging and diffusion tensor imaging for the diagnosis of liver fibrosis and inflammation. J. Magn. Reson. Imaging 2008, 28, 89-95. [CrossRef] [PubMed]

4. Hagiwara, M.; Rusinek, H.; Lee, V.S.; Losada, M.; Bannan, M.A.; Krinsky, G.A.; Taouli, B. Advanced liver fibrosis: Diagnosis with 3D whole-liver perfusion MR imaging-Initial experience. Radiology 2008, 246, 926-934. [CrossRef] [PubMed]

5. Kim, H.; Taksali, S.E.; Dufour, S.; Befroy, D.; Goodman, T.R.; Petersen, K.F.; Shulman, G.I.; Caprio, S.; Constable, R.T. Comparative MR study of hepatic fat quantification using single-voxel proton spectroscopy, two-point dixon and three-point IDEAL. Magn. Reson. Med. 2008, 59, 521-527. [CrossRef] [PubMed]

6. Foucher, J.; Chanteloup, E.; Vergniol, J.; Castera, L.; Le Bail, B.; Adhoute, X.; Bertet, J.; Couzigou, P.; de Ledinghen, V. Diagnosis of cirrhosis by transient elastography (FibroScan): A prospective study. Gut 2006, 55, 403-408. [CrossRef] 
7. Jia, J.; Hou, J.; Ding, H.; Chen, G.; Xie, Q.; Wang, Y.; Zeng, M.; Zhao, J.; Wang, T.; Hu, X.; et al. Transient elastography compared to serum markers to predict liver fibrosis in a cohort of Chinese patients with chronic hepatitis B. J. Gastroenterol. Hepatol. 2015, 30, 756-762. [CrossRef]

8. Foucher, J.; Castera, L.; Bernard, P.H.; Adhoute, X.; Laharie, D.; Bertet, J.; Couzigou, P.; de Ledinghen, V. Prevalence and factors associated with failure of liver stiffness measurement using FibroScan in a prospective study of 2114 examinations. Eur. J. Gastroenterol. Hepatol. 2006, 18, 411-412. [CrossRef]

9. Bonekamp, D.; Bonekamp, S.; Ou, H.Y.; Torbenson, M.S.; Corona-Villalobos, C.P.; Mezey, E.; Kamel, I.R. Assessing liver fibrosis: Comparison of arterial enhancement fraction and diffusion-weighted imaging. J. Magn. Reson. Imaging 2014, 40,1137-1146. [CrossRef]

10. Tosun, M.; Inan, N.; Sarisoy, H.T.; Akansel, G.; Gumustas, S.; Gurbuz, Y.; Demirci, A. Diagnostic performance of conventional diffusion weighted imaging and diffusion tensor imaging for the liver fibrosis and inflammation. Eur. J. Radiol. 2013, 82, 203-207. [CrossRef]

11. Bulow, R.; Mensel, B.; Meffert, P.; Hernando, D.; Evert, M.; Kuhn, J.P. Diffusion-weighted magnetic resonance imaging for staging liver fibrosis is less reliable in the presence of fat and iron. Eur. Radiol. 2013, 23, 1281-1287. [CrossRef] [PubMed]

12. Rosenkrantz, A.B.; Oei, M.; Babb, J.S.; Niver, B.E.; Taouli, B. Diffusion-weighted imaging of the abdomen at 3.0 Tesla: Image quality and apparent diffusion coefficient reproducibility compared with 1.5 Tesla. J. Magn. Reson. Imaging 2011, 33, 128-135. [CrossRef] [PubMed]

13. Zhang, J.L.; Sigmund, E.E.; Chandarana, H.; Rusinek, H.; Chen, Q.; Vivier, P.H.; Taouli, B.; Lee, V.S. Variability of renal apparent diffusion coefficients: Limitations of the monoexponential model for diffusion quantification. Radiology 2010, 254, 783-792. [CrossRef] [PubMed]

14. Song, J.S.; Kwak, H.S.; Byon, J.H.; Jin, G.Y. Diffusion-weighted MR imaging of upper abdominal organs at different time points: Apparent diffusion coefficient normalization using a reference organ. J. Magn. Reson. Imaging 2017, 45, 1494-1501. [CrossRef] [PubMed]

15. Do, R.K.; Chandarana, H.; Felker, E.; Hajdu, C.H.; Babb, J.S.; Kim, D.; Taouli, B. Diagnosis of liver fibrosis and cirrhosis with diffusion-weighted imaging: Value of normalized apparent diffusion coefficient using the spleen as reference organ. Am. J. Roentgenol. 2010, 195, 671-676. [CrossRef]

16. Castera, L. Noninvasive Assessment of Liver Fibrosis. Dig. Dis. 2015, 33, 498-503. [CrossRef]

17. DeLong, E.R.; DeLong, D.M.; Clarke-Pearson, D.L. Comparing the areas under two or more correlated receiver operating characteristic curves: A nonparametric approach. Biometrics 1988, 44, 837-845. [CrossRef]

18. Wang, Y.; Ganger, D.R.; Levitsky, J.; Sternick, L.A.; McCarthy, R.J.; Chen, Z.E.; Fasanati, C.W.; Bolster, B.; Shah, S.; Zuehlsdorff, S.; et al. Assessment of chronic hepatitis and fibrosis: Comparison of MR elastography and diffusion-weighted imaging. Am. J. Roentgenol. 2011, 196, 553-561. [CrossRef]

19. Braithwaite, A.C.; Dale, B.M.; Boll, D.T.; Merkle, E.M. Short- and midterm reproducibility of apparent diffusion coefficient measurements at 3.0-T diffusion-weighted imaging of the abdomen. Radiology 2009, 250, 459-465. [CrossRef]

20. Corona-Villalobos, C.P.; Pan, L.; Halappa, V.G.; Bonekamp, S.; Lorenz, C.H.; Eng, J.; Kamel, I.R. Agreement and reproducibility of apparent diffusion coefficient measurements of dual-b-value and multi-b-value diffusion-weighted magnetic resonance imaging at 1.5 Tesla in phantom and in soft tissues of the abdomen. J. Comput. Assist. Tomogr. 2013, 37, 46-51. [CrossRef]

21. Ghany, M.G.; Strader, D.B.; Thomas, D.L.; Seeff, L.B. American Association for the Study of Liver, D. Diagnosis, management, and treatment of hepatitis C: An update. Hepatology 2009, 49, 1335-1374. [CrossRef] [PubMed]

22. Taouli, B.; Tolia, A.J.; Losada, M.; Babb, J.S.; Chan, E.S.; Bannan, M.A.; Tobias, H. Diffusion-weighted MRI for quantification of liver fibrosis: Preliminary experience. Am. J. Roentgenol. 2007, 189, 799-806. [CrossRef] [PubMed] 
23. Friedrich-Rust, M.; Poynard, T.; Castera, L. Critical comparison of elastography methods to assess chronic liver disease. Nat. Rev. Gastroenterol. Hepatol. 2016, 13, 402-411. [CrossRef] [PubMed]

24. Colagrande, S.; Mazzoni, L.N.; Mazzoni, E.; Pradella, S. Effects of gadoxetic acid on quantitative diffusion-weighted imaging of the liver. J. Magn. Reson. Imaging 2013, 38, 365-370. [CrossRef] [PubMed]

(C) 2019 by the authors. Licensee MDPI, Basel, Switzerland. This article is an open access article distributed under the terms and conditions of the Creative Commons Attribution (CC BY) license (http://creativecommons.org/licenses/by/4.0/). 